\title{
Clinical characteristics of bacterial vaginosis among women testing positive for fastidious bacteria
}

\author{
C L Haggerty, ${ }^{1}$ P A Totten, ${ }^{2}$ M Ferris, ${ }^{3}$ D H Martin, ${ }^{3}$ S Hoferka, ${ }^{1}$ S G Astete, ${ }^{2}$ \\ R Ondondo, ${ }^{2} \mathrm{~J}$ Norori, ${ }^{3} \mathrm{R}$ B Ness ${ }^{1}$
}

\section{See Editorial, p 240}

${ }^{1}$ University of Pittsburgh, Pittsburgh, Philadelphia, USA;

${ }^{2}$ Department of Medicine, Division of Infectious Diseases, University of Washington, Seattle, Washington, USA

${ }^{3}$ Research Institute for Children, Departments of Pediatrics and Microbiology, LSUHSC, New Orleans, Louisiana, USA

Correspondence to: Dr C L Haggerty, University of Pittsburgh, Department of Epidemiology, 130 DeSoto Street, 516B Parran Hall, Pittsburgh, PA 15261, USA; haggerty@pitt.edu

Accepted 13 October 2008 Published Online First 12 November 2008

\section{UNLOCKE}

This paper is freely available online under the BMJ Journals unlocked scheme, see http:// sti.bmj.com/info/unlocked.dtl

\begin{abstract}
Objectives: As the aetiology of bacterial vaginosis (BV) is not well understood, this study sought to determine the relationships between several fastidious microbes, BV and selected clinical characteristics of BV.

Methods: Endometrial and cervical specimens from 50 women with non-gonococcal, non-chlamydial endometritis were tested for Leptotrichia sanguinegens/amnionii, Atopobium vaginae, bacterial vaginosis-associated bacteria 1 (BVAB1), Ureaplasma urea/yticum biovar 2 (UU-2) and Ureaplasma parvum using PCR. BV was categorised using Nugent's and Amsel's criteria. Odds ratios (OR) adjusted for age and race were estimated using multivariable logistic regression.
\end{abstract}

Results: Although elevated pH was a universal feature, other BV characteristics differed by pathogen, suggesting variable clinical presentation. Only UU-2 was strongly associated with vaginal discharge, but a positive whiff test and a 20\% or greater classification of epithelial cells as clue cells were more common among women with $L$ sanguinegens/amnionii, A vaginae and BVAB1. For each of these bacteria, there were trends towards associations with BV defined by Amsel's criteria (L sanguinegens/ amnionii OR 2.9, 95\% $\mathrm{Cl} 0.5$ to 15.7; A vaginae OR 2.6, $95 \% \mathrm{Cl} 0.6$ to 11.4 ; BVAB1 OR 5.7, $95 \% \mathrm{Cl} 1.0$ to 31.1 ) and significant associations with $\mathrm{BV}$ defined by Gram stain (L sanguinegens/amnionii OR 17.7, 95\% Cl 2.8 to 113.0; A vaginae OR 19.2, $95 \% \mathrm{Cl} 3.7$ to 98.7; BVAB1 OR 21.1, $95 \% \mathrm{Cl} 2.2$ to 198.5$)$.

Conclusions: $L$ sanguinegens/amnionii, $A$ vaginae and BVAB1 are associated with clinical characteristics consistent with BV and BV defined by Nugent's and Amsel's criteria. These fastidious bacteria may cause unrecognised infection, as none was associated with abnormal vaginal discharge.

Bacterial vaginosis (BV) is a common lower genital tract infection that may lead to pelvic inflammatory disease (PID), ${ }^{1}$ subsequent infertility ${ }^{2}$ and preterm birth, ${ }^{3}$ and may increase susceptibility to HIV. ${ }^{4}$ Although no single agent is known to cause BV and its aetiology is not well understood, bacteria such as Gardnerella vaginalis, ureaplasmas, Mycoplasma hominis and anaerobic bacteria are commonly isolated from BV patients. ${ }^{5-7}$ Until recently, our understanding of BV microbiology largely came from cultivated species and Gramstained vaginal smear analysis, most notably Nugent's criteria. ${ }^{8}$ Recently, cultivation-independent studies using $16 \mathrm{~S}$ rDNA sequences PCR amplified from vaginal DNA have revealed previously unrecognised bacterial genera associated with BV. Some of these include metronidazoleresistant ${ }^{5}$ Atopobium vaginae, ${ }^{569}$ Leptotrichia
(Sneathia) sanguinegens and Leptotrichia amnionii, ${ }^{6}$ and three new species of uncultivated bacteria termed bacterial vaginosis-associated bacteria (BVAB) types 1,2 and $3 .{ }^{6}$

Nugent's criteria $^{8}$ measure specific Gramstained bacterial morphotypes. Consequently, organisms that do not Gram stain, such as ureaplasmas and mycoplasmas, are not measured. Ureaplasmas have been associated with $\mathrm{BV},{ }^{10}$ although modestly in some studies. ${ }^{7}$ High rates of ureaplasma colonisation among patients without clinical disease further complicate interpretation. ${ }^{10} 11$ Moreover, ureaplasmas (formerly designated Ureaplasma urealyticum but termed undifferentiated ureaplasmas herein) have recently been split into two biovars: Ureaplasma parvum, reported to be non-pathogenic in men; ${ }^{12}$ and $U$ urealyticum (biovar 2), associated with urethritis. ${ }^{12}{ }^{13}$ The role of these newly classified ureaplasmas in BV has been little studied. In this analysis, we sought to determine the associations among several fastidious pathogens and BV defined by Gram stain and Amsel's criteria among a population of women with PID.

\section{MATERIALS AND METHODS \\ Population}

A subset of previously collected and stored cervical and endometrial specimens from women who participated in the PID Evaluation and Clinical Health (PEACH) Study ${ }^{14}$ was analysed. Briefly, the parent PEACH study recruited 831 women aged 14-37 years with clinically suspected PID between March 1996 and February 1999 from emergency departments, obstetrics and gynaecology clinics, sexually transmitted infection (STI) clinics and private practices at 13 US clinical sites. All women gave written informed consent, and University of Pittsburgh Institutional Review Board approval was obtained for both the PEACH study and the substudy described herein. In order to examine the lower and upper genital tract microbiological milieu among women with non-gonococcal, nonchlamydial PID, and additionally to examine the associations between selected fastidious bacteria and BV, we conducted a targeted PCR substudy using stored specimens from 50 randomly selected women with histologically confirmed non-gonococcal, non-chlamydial endometritis. A classification of endometritis was given upon finding at least five neutrophils in the endometrial surface epithelium in the absence of menstrual endometrium and/or at least two plasma cells in the endometrial stroma. ${ }^{15}$ 


\section{Microbiological studies}

As part of the current substudy, previously frozen endometrial biopsy and cervical swab specimens were tested for $L$ sanguinegens/amnionii, A vaginae, BVAB1, $U$ urealyticum (biovar 2 ), and $U$ parvum using PCR assays. Patient specimens were purified using the MasterPure DNA purification kit (Epicentre, Madison, Wisconsin, USA). For the Leptotrichia PCR assay, the published Leptotrichia-specific primers ${ }^{6}$ were optimised for our thermocycling conditions. Leptotrichia-specific PCR products were detected as approximately $240 \mathrm{bp}$ products on agarose gels. The specificity of this assay was confirmed by sequencing the PCR products from four randomly selected specimens; two of the specimens contained sequences consistent with $L$ amnionii and two contained sequences consistent with $L$ sanguinegens.

PCR primers targeting the $16 \mathrm{~S}$ rRNA genes of $A$ vaginae ${ }^{5}$ and BVAB1 $^{6}$ were 5'-GTTAGGTCAGGAGTTAAATCTG-3' and 5'-TCATGGCCCAGACC-3' and 5'-AGTGTAGGCGGCACTATAAG-3' and 5'-CGATAACTGACGCTAAGGCT-3', respectively. The PCR conditions were $95^{\circ} \mathrm{C}$ ( 5 minutes) followed by 25 cycles of $95^{\circ} \mathrm{C}(1$ minute $), 62^{\circ} \mathrm{C}(1$ minute $) A$ vaginae or $66^{\circ} \mathrm{C}$ (1 minute) for $\mathrm{BVAB} 1,72^{\circ} \mathrm{C}$ (1 minute) with final extension $72^{\circ} \mathrm{C}$ for 7 minutes. PCR products (150-200 bp) were visualised on agarose gels sequenced to confirm specificity.

The $U$ urealyticum (biovar 2) PCR assay was designed to differentiate the newly recognised species of ureaplasma, $U$ urealyticum and $U$ parvum, formally called $U$ urealyticum biovar 2 and biovar 1 , respectively. The $U$ urealyticum PCR targets sequences in the urease genes of all 10 serovars of UU-2 not found in the four $U$ parvum (biovar 1) serovars. Conversely, the $U$ parvum PCR targets sequences in the urease genes of all $U$ parvum serotypes not found in the UU-2 serovars. In both assays, $5 \mu \mathrm{l}$ purified patient sample was subjected to PCR amplification in a total volume of $100 \mu \mathrm{l}$ containing $1 \times$ PCR buffer (magnesium ion free; Promega, Madison, Wisconsin, USA), $2.75 \mathrm{mmol}$ magnesium chloride, $200 \mu \mathrm{mol}$ each of the four dNTP, $0.1 \mu \mathrm{mol}$ forward primer, $0.1 \mu \mathrm{mol}$ reverse primer and $5 \mathrm{U}$ of Taq DNA polymerase. PCR primers and amplification conditions for the $U$ urealyticum PCR were: UUF2 (5'-CAC AGA TGT CCT TGA TGT ACC C-3') and UUR2 (5'-GTA AAA ATT ATT TGT AAA TTG GGC-3'); and the following temperatures: $94^{\circ} \mathrm{C}$ for 4 minutes; 45 cycles of $94^{\circ} \mathrm{C}$ for $10 \mathrm{~s}, 56^{\circ} \mathrm{C}$ for $50 \mathrm{~s}$ and $72^{\circ} \mathrm{C}$ for $30 \mathrm{~s}$; followed by $72^{\circ} \mathrm{C}$ for 5 minutes and a final soak set at $4^{\circ} \mathrm{C}$ indefinitely. Primers and conditions for the $U$ parvum PCR were UpF1 (5'-GATCCAATTTACAAATAACA-3') and UpR1 (5'-GTAGAAACTTGTAAAATAGAG-3'); and $94^{\circ} \mathrm{C}$ for 4 minutes; cycle programme ( 35 cycles); $94^{\circ} \mathrm{C}, 45^{\circ} \mathrm{C}$ and $72^{\circ} \mathrm{C}$ for 1 minute each; followed by $72^{\circ} \mathrm{C}$ for 10 minutes and a final soak set at $4^{\circ} \mathrm{C}$ indefinitely. Assay specificities were confirmed by the detection of the appropriate sized PCR product (474 and 469 for Uurealyticum and U parvum) on agarose gels and reactivity with the UU-2-specific probe (UUDP2 (5'-biotin-ATC CAA AAG TTA TTG GTA ACA GTA G-3') and U parvum (5'-biotin-GGCAATTAATTTCGCTAGT-3')-specific probes on Southern blots hybridised at $55^{\circ} \mathrm{C}$ and $50^{\circ} \mathrm{C}$, respectively, and visualised on Kodak BioMax XAR film after reaction in the chemiluminescence assay using the ECL kit (Amersham GE Healthcare, Little Chalfont, UK).

In a subset of 352 women in the PEACH study, endometrial biopsy tissue specimens were examined for anaerobic Gramnegative rods, $G$ vaginalis and $M$ hominis. Twenty-nine women in the current substudy had culture results. One sample was used to inoculate a human blood bilayer Tween agar ${ }^{16}$ for the detection of $G$ vaginalis, and a second swab sample was used to inoculate a Brucella agar for recovery of anaerobic bacteria and broth media for $M$ hominis recovery.

Vaginal fluid was analysed for bacterial vaginosis by Amsel's criteria $^{17}$ and by Nugent's criteria, in which the relative presence of morphotypes consistent with Lactobacillus spp, Gardnerella spp, Mobiluncus and anaerobic bacteria is measured by Gram stain with a score ranging from 0 to $10 .^{8}$

\section{Statistical analysis}

Comparisons of demographic, sexual and behavioural characteristics, and cultivable comorbid BV bacteria were compared between women with and without $L$ sanguinegens/amnionii, $A$ vaginae, BVAB1, UU-2 and $U$ parvum using $\chi^{2}$ tests of proportions and Fisher's exact tests. Logistic regression models were fit with BV as the dependent variable and Leptotrichia, A vaginae, BVAB1, UU-2 and U parvum as explanatory variables. Odds ratios (OR) adjusted for age and race were estimated using multivariable logistic regression. Analyses were performed using SAS version 9.1 for Windows.

\section{RESULTS}

All bacteria analysed were common among women with PID. $L$ sanguinegens/amnionii, A vaginae, BVAB1, UU-2, and U parvum were detected in $62 \%, 54 \%, 28 \%, 32 \%$ and $32 \%$ of women tested, respectively. There was a high degree of agreement between cervical and endometrial PCR (Leptotrichia: Phi coefficient 0.75, $\mathrm{p}<0.001$; BVAB1: Phi coefficient 0.33, $\mathrm{p}<0.05$; $U$ ureaplasma (biovar 2): Phi coefficient 0.49, $\mathrm{p}<0.005$; and $U$ parvum Phi coefficient 0.31, $p<0.05$ ). All endometrial Leptotrichia, BVAB1, U ureaplasma (biovar 2) and $U$ parvum-positive cases were also positive at the cervix. Seventyseven per cent of Leptotrichia, 14\% of BVAB1, 31\% of $U$ ureaplasma (biovar 2 ) and $13 \%$ of $U$ parvum cervical positive cases were also positive in the endometrium. Although the relationship between cervical and endometrial PCR was not statistically significant, $80 \%$ of endometrial $A$ vaginae-positive cases were also positive at the cervix and $15 \%$ of cervical positive cases were positive in the endometrium.

Demographic characteristics and variables comparing medical, sexual and behavioural history stratified by bacteria detected are presented in table 1 . Women who tested positive for $L$ sanguinegens/amnionii were significantly more likely to be black (OR 4.9, 95\% CI 1.4 to 16.9) and to have douched within the last month (OR 3.1, 95\% CI 1.0 to 10.2). Similarly, women who tested positive for $A$ vaginae were more likely to be uninsured (OR 6.1, 95\% CI 1.2 to 30.1), report a history of Trichomonas vaginalis (OR 9.3, 95\% CI 1.1 to 80.9) and to have douched in the last month (OR 3.1, 95\% CI 1.0 to 9.9). None of the characteristics analysed were statistically associated with UU-2, U parvum, or BVAB1. Characteristic profiles were similar to those among women with positive $M$ hominis and $G$ vaginalis cultures, bacteria traditionally associated with BV, although cell sizes were small and not all comparisons were statistically significant (table 2). In addition, women testing positive for $M$ hominis were 18 times as likely to report a history of PID (OR 18.0, 95\% CI 1.1 to 299.0 ).

Anaerobic bacteria, $M$ hominis and $G$ vaginalis were detected more often in women with $L$ sanguinegens/amnionii and $A$ vaginae, although only the association between Leptotrichia and anaerobic bacteria was statistically significant (table 3). G vaginalis was cultured from the endometrium significantly more often among women testing positive for $U$ parvum, but not among women testing positive for UU-2. BVAB1 was not 


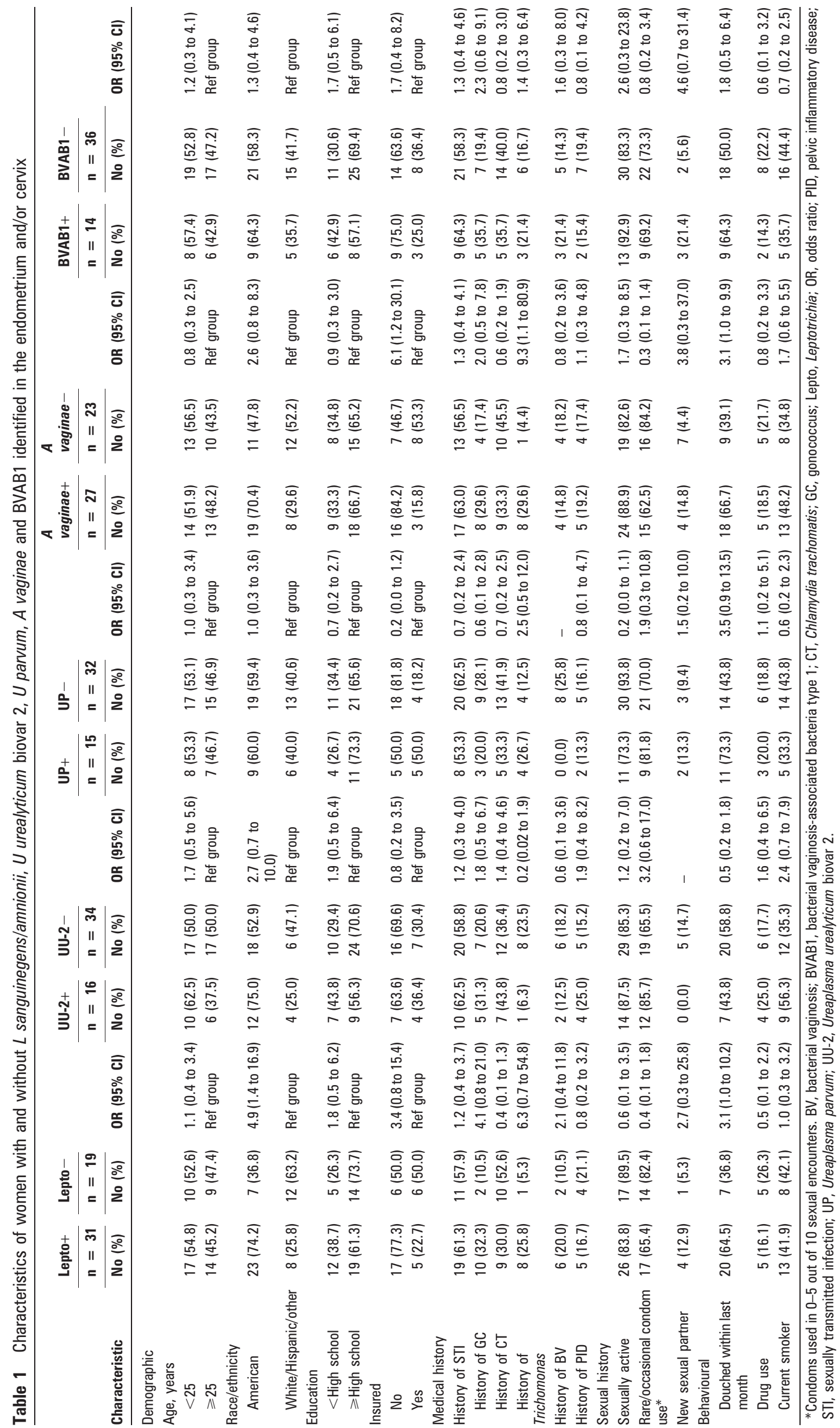


Table 2 Characteristics of women with and without $M$ hominis and $G$ vaginalis cultured from the endometrium

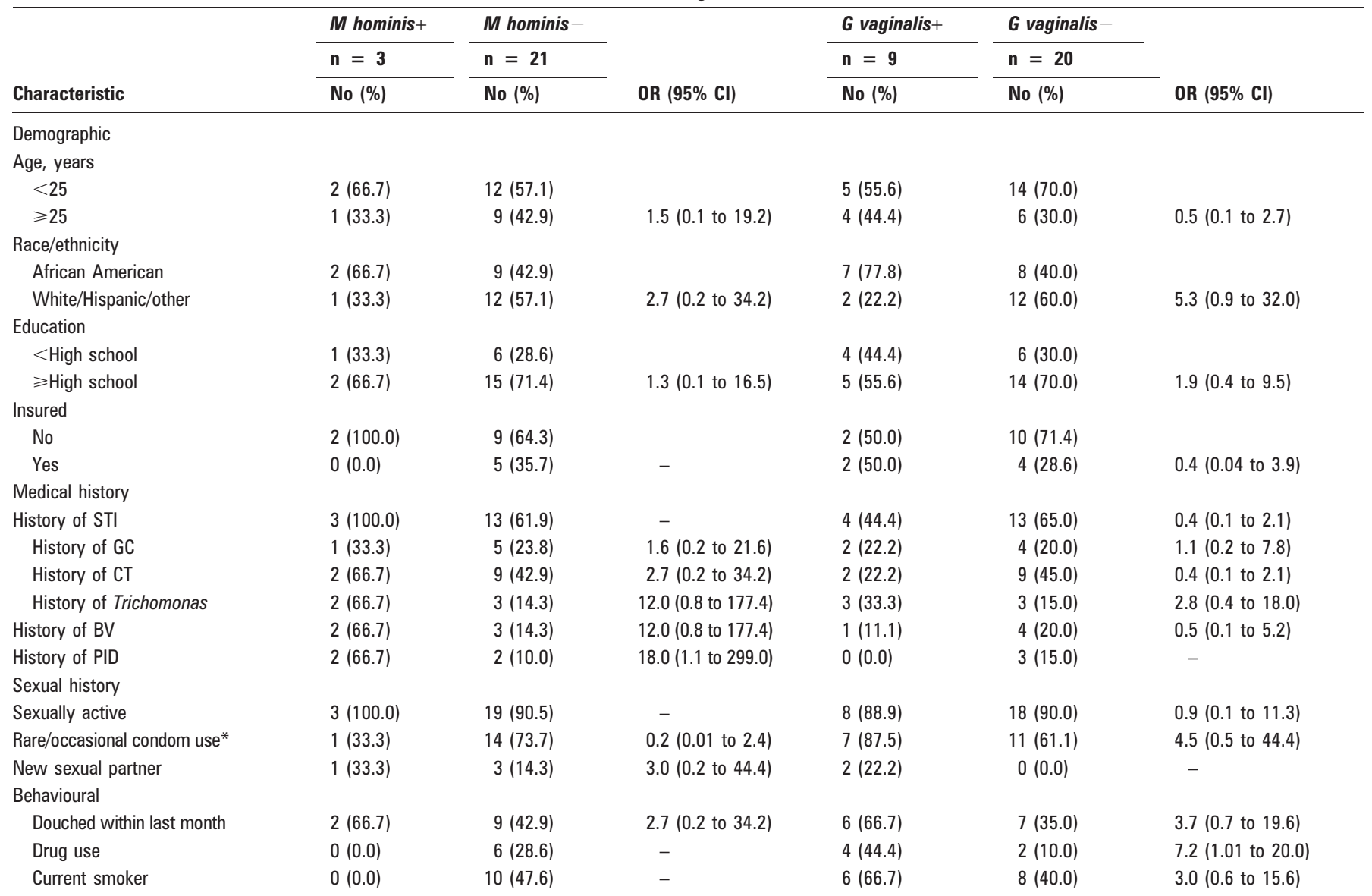

*Condoms used in 0-5 out of 10 sexual encounters. BV, bacterial vaginosis; CT, Chlamydia trachomatis; GC, gonococcus; OR, odds ratio; PID, pelvic inflammatory disease; STI, sexually transmitted infection.

significantly associated with any of the cultivable BV pathogens considered in our analyses.

Women in whom $L$ sanguinegens/amnionii, A vaginae and BVAB1 were detected were generally more likely to have each of Amsel's criteria for BV, although not all associations were statistically significant (see table 4). All bacteria except for $U$ ureaplasma (biovar 2) and $U$ parvum were more likely to be categorised as having BV defined both by Amsel's criteria ( $L$ sanguinegens/amnionii adjusted OR 2.9, 95\% CI 0.5 to $15.7 ; A$. vaginae adjusted OR 2.6, 95\% CI 0.6 to 11.4; and BVAB1 adjusted OR 5.7, 95\% CI 1.0 to 31.1) and by Nugent's Gram stain criteria ( $L$ sanguinegens/amnionii adjusted OR 17.7, 95\% CI 2.8 to 113.0; A vaginae adjusted OR 19.2, 95\% CI 3.7 to 98.7; and BVAB1 adjusted OR 21.1, 95\% CI 2.2 to 198.5). Results were generally similar to those for $M$ hominis and $G$ vaginalis, established BV-associated species, although cell sizes for comparisons of these cultured bacteria were small and not all comparisons were statistically significant.

\section{DISCUSSION}

We conclude that $L$ sanguinegens/amnionii, A vaginae and BVAB1 are associated with BV defined by Gram stain and Amsel's criteria among women with histologically confirmed PID. Consistent results using varying BV definitions suggest robust findings. Our results agree with those reported by Ferris et al, ${ }^{5}$ in which $A$ vaginae was present in $55 \%$ of $\mathrm{BV}$ patients compared with $8 \%$ of controls and Fredricks et al, ${ }^{6}$ in which $A$ vaginae, Leptotrichia and BVAB were all associated with BV defined using
Amsel's criteria. The role of newly classified ureaplasma biovars in BV has not been widely studied, and to our knowledge, ours is the first to compare BV among women with and without $U$ parvum. Our null finding is consistent with evidence demonstrating no relationship between $U$ parvum and urethritis in men. ${ }^{12}$ Only one published study has examined the relationship between UU-2 and BV, reporting that among 49 women delivering preterm, UU-2 was more frequent among those with compared with those without clinically diagnosed BV (OR 15.0, 95\% CI 1.2 to 209.0). ${ }^{18}$ Although BV by Amsel's and Nugent's criteria were both more common among women testing positive for UU-2, compared with women testing negative for this bacteria ( $57 \%$ vs $50 \%$ and $64 \%$ vs $53 \%$, respectively), these differences were modest and not statistically different in our study.

To our knowledge, our study is the first to compare a range of clinical characteristics consistent with BV among women with and without these fastidious bacteria. Although L sanguinegens/ amnionii, A vaginae and BVAB1 were all associated with BV defined using both Nugent's and Amsel's criteria, and elevated $\mathrm{pH}$ was a universal feature, other BV characteristics differed by pathogen, suggesting variable clinical presentations. Only UU-2 was associated with vaginal discharge, whereas a positive whiff test was significantly more common among women testing positive for BVAB1, and a $20 \%$ or greater classification of epithelial cells as clue cells was more common among women testing positive for $L$ sanguinegens/amnionii, A vaginae, or BVAB1. As UU-2 has been associated with urethritis in men, ${ }^{12}{ }^{13}$ and it was associated with vaginal discharge and elevated $\mathrm{pH}$ but had the weakest relationship with the 


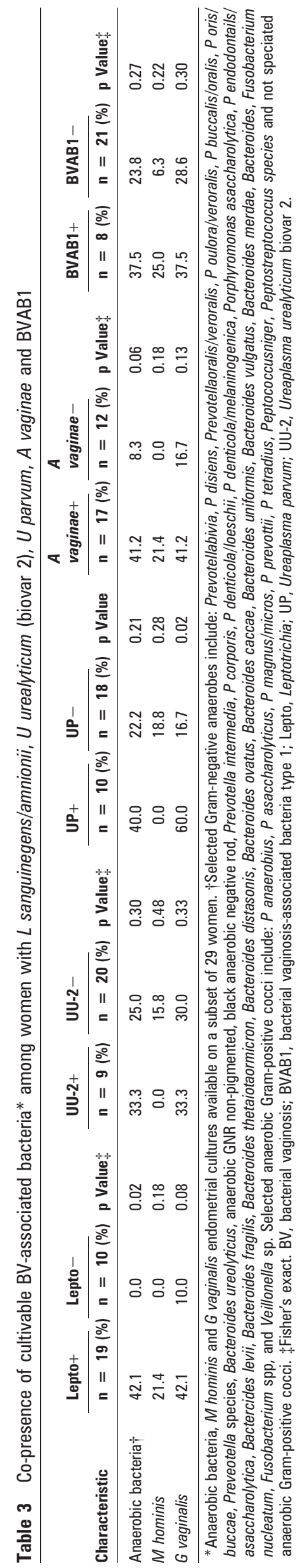

remaining $\mathrm{BV}$ characteristics, it is tempting to speculate that this bacterium could be associated with cervicitis. With the exception of $M$ hominis, none of the bacteria studied were associated with a history of BV, suggesting the possibility of previous asymptomatic $\mathrm{BV}$ among women with Leptotrichia, $A$ vaginae and BVAB1. The relationship between BVAB1 and clue cells is supported by a fluorescence in-situ hybridisation study published by Fredricks and colleagues, ${ }^{6}$ in which BVAB were found to attach to vaginal epithelial cells, similar to the clue cells characteristic of BV.

Our findings suggest that $L$ sanguinegens/amnionii and $A$ vaginae may be associated with sexual activity, as characteristics associated with STI, including uninsured status, STI history and report of a new sexual partner, were associated with these bacteria, although not all comparisons were statistically significant. Data supporting sexual activity associations with ureaplasmas and BVAB were less compelling. Women testing positive for Leptotrichia were nearly five times as likely to be African-American, although no other bacteria were significantly associated with race. Douching was among the strongest risk factors in our study, with women harbouring $L$ sanguinegens/ amnionii and $A$ vaginae being three times more likely to report douching, although confidence intervals included one demonstrating borderline associations. Similarly, women with BVAB1 were almost twice as likely to report douching, although this difference was not significant. These findings are consistent with evidence showing that douching, through alteration of the vaginal flora, is associated with BV. ${ }^{19}$

It is possible that although these novel bacteria are frequent among women with $\mathrm{BV}$, they do not play a pathogenic role. A limitation of our pilot study is the small sample size and the culture of $G$ vaginalis and $M$ hominis in only a subset of the parent study, which did not allow adjustment for other pathogens. The associations between Leptotrichia, A vaginae, BVAB1 and BV by Gram stain may merely suggest that these bacteria frequently co-inhabit the lower genital tract of women with other BV pathogens. In fact, our study shows that $G$ vaginalis, anaerobic bacteria and $M$ hominis are more common among women with compared with women without $L$ sanguinegens/amnionii and $A$ vaginae. This supposition is supported by a study of 55 women attending a gynaecology outpatients clinic, in which $50 \%$ of $A$ vaginae patients were found to co-harbour $G$ vaginalis, an organism frequently identified among women with BV. ${ }^{20}$ In addition, biofilms composed of both $G$ vaginalis and $A$ vaginae are prominent among women with BV. ${ }^{21}$ Alternatively, $G$ vaginalis may not be pathogenic, but rather a marker for infection with other fastidious bacteria, because $G$ vaginalis is also frequent among women without $\mathrm{BV}^{6}$ and is not associated with other reproductive morbidity.

$\mathrm{BV}$ and $\mathrm{BV}$-associated microorganisms are associated with PID, ${ }^{1}$ although the microbial aetiology of non-gonococcal, nonchlamydial PID is not completely characterised. As $L$ sanguinegens/amnionii, A vaginae, BVAB1, UU-2 and $U$ parvum were highly prevalent, our findings suggest that several newly recognised species may play a role in the aetiology of a significant number of non-gonococcal, non-chlamydial PID cases. Although cross-sectional, our findings also suggest that these pathogens may ascend from the lower to the upper genital tract, as evidenced by a high degree of agreement between cervical and endometrial PCR. The quest to determine novel PID pathogens is of great interest, as Neisseria gonorrhoeae and/ or Chlamydia trachomatis are only recovered from approximately a third to a half of women with PID, ${ }^{19}{ }^{22}$ resulting in an 
Table 4 Associations between fastidious bacteria identified by PCR, cultured bacteria and bacterial vaginosis determined by Gram stain and Amsel's criteria

\begin{tabular}{|c|c|c|c|c|}
\hline Bacterial vaginosis variable & Positive \% & Negative \% & $\begin{array}{l}\text { Crude OR } \\
(95 \% \mathrm{CI})\end{array}$ & $\begin{array}{l}\text { Adjusted OR* } \\
(95 \% \mathrm{CI})\end{array}$ \\
\hline \multicolumn{5}{|l|}{ L sanguinegens/amnionii } \\
\hline Discharge & 41.9 & 38.9 & $1.1(0.4$ to 3.7$)$ & 0.8 (0.2 to 2.9$)$ \\
\hline Vaginal ph $>4.5$ & 95.7 & 68.8 & $10.0(1.0$ to 96.4$)$ & $14.5(1.2$ to 173.0$)$ \\
\hline Whiff test & 51.6 & 36.8 & $1.8(0.6$ to 5.9$)$ & $1.8(0.5$ to 6.6$)$ \\
\hline Clue cells $>20 \%$ & 63.3 & 31.6 & $3.7(1.1$ to 12.7$)$ & $5.7(1.3$ to 25.0$)$ \\
\hline BV: Amsel's criteria & 60.9 & 40.0 & $2.3(0.6$ to 8.8$)$ & $2.9(0.5$ to 15.7$)$ \\
\hline BV: Nugent's criteria & 75.0 & 25.0 & $9.0(2.2$ to 37.2$)$ & 17.7 (2.8 to 113.0$)$ \\
\hline \multicolumn{5}{|l|}{ UU-2 } \\
\hline Discharge & 62.5 & 30.3 & $3.8(1.1$ to 13.5$)$ & 3.4 (0.93 to 12.41$)$ \\
\hline Vaginal $\mathrm{ph}>4.5$ & 100.0 & 76.0 & - & - \\
\hline Whiff test & 50.0 & 44.1 & $1.3(0.4$ to 4.2$)$ & $1.3(0.4$ to 4.7$)$ \\
\hline Clue cells $>20 \%$ & 43.8 & 54.6 & $0.7(0.2$ to 2.2$)$ & $0.7(0.2$ to 2.4$)$ \\
\hline BV: Amsel's criteria & 57.1 & 50.0 & $1.3(0.4$ to 5.1$)$ & $1.5(0.3$ to 6.8$)$ \\
\hline BV: Nugent's criteria & 64.3 & 53.3 & $1.6(0.4$ to 5.8$)$ & $1.7(0.4$ to 6.9$)$ \\
\hline \multicolumn{5}{|l|}{ UP } \\
\hline Discharge & 35.7 & 40.6 & $0.8(0.2$ to 3.0$)$ & $0.8(0.2$ to 2.9$)$ \\
\hline Vaginal ph $>4.5$ & 81.8 & 88.5 & $0.6(0.1$ to 4.$)$ & $0.4(0.04$ to 3.8$)$ \\
\hline Whiff test & 33.3 & 50.0 & $0.5(0.1$ to 1.8$)$ & $0.5(0.1$ to 1.8$)$ \\
\hline Clue cells $>20 \%$ & 46.7 & 54.8 & $0.7(0.2$ to 2.5$)$ & $0.7(0.2$ to 2.5$)$ \\
\hline BV: Amsel's criteria & 40.0 & 57.7 & $0.5(0.1$ to 2.2$)$ & $0.4(0.1$ to 2.3$)$ \\
\hline BV: Nugent's criteria & 61.5 & 55.2 & $1.3(0.3$ to 4.9$)$ & $1.4(0.4$ to 5.3$)$ \\
\hline \multicolumn{5}{|l|}{$A$ vaginae } \\
\hline Discharge & 44.4 & 36.4 & $1.4(0.4$ to 4.4$)$ & $1.2(0.35$ to 3.93$)$ \\
\hline Vaginal ph $>4.5$ & 100.0 & 64.7 & - & - \\
\hline Whiff test & 59.3 & 30.4 & $3.3(1.0$ to 10.8$)$ & $3.3(1.0$ to 11.3$)$ \\
\hline Clue cells $>20 \%$ & 66.7 & 31.8 & $4.3(1.3$ to 14.3$)$ & $4.5(1.3$ to 16.0$)$ \\
\hline BV: Amsel's criteria & 63.6 & 37.5 & $2.9(0.8$ to 11.1$)$ & $2.6(0.6$ to 11.4$)$ \\
\hline BV: Nugent's criteria & 83.3 & 25.0 & 15.0 (3.4 to 65.6$)$ & 19.2 (3.7 to 98.7 ) \\
\hline \multicolumn{5}{|l|}{ BVAB1 } \\
\hline Discharge & 50.0 & 37.1 & $1.7(0.5$ to 5.9$)$ & $1.7(0.5$ to 6.0$)$ \\
\hline Vaginal ph $>4.5$ & 100.0 & 76.9 & - & - \\
\hline Whiff test & 78.6 & 33.3 & $7.3(1.7$ to 31.3$)$ & $8.7(1.9$ to 40.4$)$ \\
\hline Clue cells $>20 \%$ & 85.7 & 37.1 & $10.2(2.0$ to 52.7$)$ & $12.6(2.2$ to 71.4$)$ \\
\hline BV: Amsel's criteria & 76.9 & 40.0 & 5.0 (1.1 to 22.8$)$ & 5.7 (1.0 to 31.1$)$ \\
\hline BV: Nugent's criteria & 92.3 & 41.9 & $16.6(1.9$ to 144.2$)$ & $21.1(2.2$ to 198.5$)$ \\
\hline \multicolumn{5}{|l|}{$M$ hominis } \\
\hline Discharge & 66.7 & 35.0 & $3.7(0.3$ to 48.6$)$ & $3.6(0.3$ to 50.1$)$ \\
\hline Vaginal ph $>4.5$ & 100.0 & 84.2 & - & - \\
\hline Whiff test & 100.0 & 47.6 & - & - \\
\hline Clue cells $>\mathbf{2 0} \%$ & 100.0 & 57.1 & - & - \\
\hline BV: Amsel's criteria & 100.0 & 100.0 & - & - \\
\hline BV: Nugent's criteria & 100.0 & 57.9 & - & - \\
\hline \multicolumn{5}{|l|}{$G$ vaginalis } \\
\hline Discharge & 33.3 & 26.3 & $1.4(0.3$ to 7.8$)$ & $1.2(0.2$ to 7.4$)$ \\
\hline Vaginal ph $>4.5$ & 85.7 & 82.4 & $1.3(0.1$ to 15.0$)$ & $0.6(0.03$ to 11.4$)$ \\
\hline Whiff test & 55.6 & 35.0 & $2.3(0.5$ to 11.5$)$ & $2.7(0.5$ to 15.8$)$ \\
\hline Clue cells $>20 \%$ & 77.8 & 40.0 & $5.3(0.9$ to 32.0$)$ & $6.1(0.9$ to 43.3$)$ \\
\hline BV: Amsel's criteria & 71.4 & 31.2 & 5.5 (0.8 to 38.7$)$ & 17.7 (1.3 to 248.1$)$ \\
\hline BV: Nugent's criteria & 88.9 & 43.8 & $10.3(1.0$ to 102.8$)$ & $6.6(0.6$ to 69.6$)$ \\
\hline
\end{tabular}

${ }^{*}$ Adjusted for age and race. BV, bacterial vaginosis; BVAB1, bacterial vaginosis-associated bacteria type 1; 0R, odds ratio; UP, Ureaplasma parvum; UU-2, Ureaplasma urealyticum biovar 2.

indeterminate microbiological aetiology in up to $70 \%$ of PID cases. Our findings support the need for additional studies examining these fastidious BV-associated bacteria among women with and without PID. Furthermore, although we could not examine gonococcal and chlamydial co-infection in our study, the possibility that infection with fastidious BVassociated bacteria may further increase the risk of upper genital tract infection among women with chlamydia or gonorrhoea should be explored in subsequent studies.
Although evidence for a role between newly identified BVassociated organisms and PID is limited, the high prevalence of these pathogens in our study is consistent with a handful of case studies, suggesting associations between $A$ vaginae and tuboovarian abscess, ${ }^{23}$ and $L$ sanguinegens/amnionii and postpartum fever, endometritis, adnexal masses and fetal death. ${ }^{24-26}$ Furthermore, in a study of 45 women with salpingitis and 44 women seeking tubal ligations, broad-range $16 \mathrm{~S}$ rDNA PCR was used to identify bacterial $16 \mathrm{~S}$ sequences in the fallopian tube 


\section{Key messages}

- L sanguinegens/amnionii, A vaginae, bacterial vaginosisassociated bacteria type 1 (BVAB1), Ureaplasma urealyticum biovar 2 and $U$ parvum were commonly identified in cervical and endometrial specimens collected from women with histologically confirmed endometritis.

- Fastidious anaerobic bacteria, including L sanguinegens/ amnionii, $A$ vaginae and BVAB1, were associated with clinical characteristics consistent with bacterial vaginosis (BV) and BV defined by Nugent's and Amsel's criteria.

- As none were associated with abnormal vaginal discharge, these anaerobes may cause unrecognised infection.

- Routine screening using targeted PCR may be warranted to prevent sequelae among asymptomatic women who would otherwise be undiagnosed.

specimens from $24 \%$ of cases and no controls. ${ }^{27}$ Bacteria phylotypes closely related to Leptotrichia spp and A vaginae were among those identified in cases.

In summary, PID patients infected with $L$ sanguinegens/ amnionii, A vaginae and BVAB1 were more likely than women testing negative by PCR to have BV. Our study suggests that although these pathogens are associated with BV, these novel bacteria may cause unrecognised infection, as none were associated with abnormal vaginal discharge and only Leptotrichia was associated with a previous history of BV. Lack of vaginal discharge may hinder patient and clinical recognition of $\mathrm{BV}$, suggesting that a number of cases may currently go undetected. As these bacteria have been found to have a high sensitivity and specificity for BV determined by Gram stain, ${ }^{28}$ routine screening using targeted PCR may be warranted to prevent sequelae among asymptomatic women who would otherwise be undiagnosed. Furthermore, current treatment regimens may be inadequate for a number of women with $\mathrm{BV}$, as $A$ vaginae has been found to be metronidazole resistant. ${ }^{5}$ As the effectiveness of currently recommended $\mathrm{BV}$ treatments for women with $L$ sanguinegens/ amnionii and BVAB is unknown, further studies are needed in order to optimise treatment and prevent sequelae.

Acknowledgements: The authors would like to thank and acknowledge the efforts of interviewers who recruited and interviewed study participants: Susan Allen, Audrey Baum, Corina Becker, Hope Cohen-Webb, Amy Cooper, Peg Crowner, Leslie Curll, Jackie Faas, Amanda Farmer, Emily Hoffman, Anne Holdredge, Alice Howell, Susan Kay, Faye Leboeuf, Ingrid Macio, Kathy Martin, Margaret McNamee, Ann Meers, Kim Miller, Andrea Montagno, Joy Mowery, Jan Mitton, Cheryl Myers, Brenda Nobels, Tara Pealer, Anne Rideout, Georgia Rothstein, Carol Sams, Tara Schuda, Buffie Schiavoni, Marsha Scott, Kelly Timbers, Sam Whitaker, Lisa Williams and MirzaVincetic. They also gratefully acknowledge consultants Tom Songer, Judy Lave and Sheryl Kelsey, and technical assistant Debra Bass.

Funding: This study was supported by grant no HS08358 from the Agency for Healthcare Research and Quality Development.

Competing interests: None.

Ethics approval: University of Pittsburgh Institutional Review Board approval was obtained.

\section{Patient consent: Obtained.}

The investigators involved in the PEACH Study include: Antonio Amortegui; Susan L Hendrix; Sharon L Hillier; Robert L Holley; Deborah B Nelson; John Nichols Jr; Jeffrey Peipert; Hugh Randall; Diane Schubeck; Steven J Sondheimer; David E Soper; Richard L Sweet; Wayne Trout; Guiliana Trucco; Harold C Wiesenfeld and Tamer Yalcinkaya.

\section{REFERENCES}

1. Haggerty CL, Hillier SL, Bass DC, et al. Bacterial vaginosis and anaerobic bacteria are associated with endometritis. Clin Infect Dis 2004;39:990-5.

2. Westrom L. Effect of acute pelvic inflammatory disease on fertility. Am J Obstet Gynecol 1975:121:707-13.

3. Klebanoff MA, Hillier SL, Nugent RP, et al. Is bacterial vaginosis a stronger risk factor for preterm birth when it is diagnosed earlier in gestation? Am J Obstet Gynecol 2005; 192:470-7.

4. Myer L, Denny L, Telerant R, et al. Bacterial vaginosis and susceptibility to HIV infection in South African women: a nested case-control study [see Comment]. $\mathrm{J}$ Infect Dis 2005;192:1372-80.

5. Ferris MJ, Masztal A, Aldridge KE, et al. Association of Atopobium vaginae, a recently described metronidazole resistant anaerobe, with bacterial vaginosis. BMC Infect Dis 2004;4:5.

6. Fredricks DN, Fiedler TL, Marrazzo JM, et al. Molecular identification of bacteria associated with bacterial vaginosis [see Comment]. N Engl J Med 2005;353:1899-911.

7. Keane FE, Thomas BJ, Gilroy CB, et al. The association of Mycoplasma hominis, Ureaplasma urealyticum and Mycoplasma genitalium with bacterial vaginosis: observations on heterosexual women and their male partners. Int J STD AIDS 2000;11:356-60.

8. Nugent RP, Krohn MA, Hillier SL. Reliability of diagnosing bacterial vaginosis is improved by a standardized Gram stain interpretation. J Clin Microbiol 1991;29:297-301.

9. Burton JP, Devillard E, Cadieux PA, et al. Detection of Atopobium vaginae in postmenopausal women by cultivation-independent methods warrants further investigation. J Clin Microbiol 2004;42:1829-31.

10. Hillier SL, Krohn MA, Rabe LK, et al. The normal vaginal flora, $\mathrm{H}_{2} \mathrm{O}_{2}$-producing lactobacilli, and bacterial vaginosis in pregnant women. Clin Infect Dis 1993;16(Suppl 4): S273-81.

11. Taylor-Robinson D, Evans RT, Coufalik ED, et al. Ureaplasma urealyticum and Mycoplasma hominis in chlamydial and non-chlamydial nongonococcal urethritis. Br J Vener Dis 1979;55:30-5.

12. Deguchi T, Yoshida T, Miyazawa T, et al. Association of Ureaplasma urealyticum (biovar 2) with nongonococcal urethritis. Sex Transm Dis 2004;31:192-5.

13. Povlsen K, Bjornelius E, Lidbrink P, et al. Relationship of Ureaplasma urealyticum biovar 2 to nongonococcal urethritis. Eur J Clin Microbiol Infect Dis 2002;21:97-101.

14. Ness RB, Soper DE, Holley RL, et al. Effectiveness of inpatient and outpatient treatment strategies for women with pelvic inflammatory disease: results from the PID Evaluation and Clinical Health (PEACH) Randomized Trial. Am J Obstet Gynecol 2002; 186:929-37.

15. Ness RB, Keder LM, Soper DE, et al. Oral contraception and the recognition of endometritis. Am J Obstet Gynecol 1997;176:580-5.

16. Totten PA, Amsel R, Hale J, et al. Selective differential human blood bilayer media for isolation of Gardnerella (Haemophilus) vaginalis. J Clin Microbiol 1982;15:141-7.

17. Amsel R, Totten PA, Spiegel CA, et al. Nonspecific vaginitis. Diagnostic criteria and microbial and epidemiologic associations. Am J Med 1983;74:14-22.

18. Povlsen K, Thorsen P, Lind I, et al. Relationship of Ureaplasma urealyticum biovars to the presence or absence of bacterial vaginosis in pregnant women and to the time of delivery. Eur J Clin Microbiol Infect Dis 2001:20:65-7.

19. Ness RB, Hillier SL, Richter HE, et al. Douching in relation to bacterial vaginosis, lactobacilli, and facultative bacteria in the vagina. Obstet Gynecol 2002;100:765-72.

20. Burton JP, Chilcott CN, Al Qumber M, et al. A preliminary survey of Atopobium vaginae in women attending the Dunedin gynaecology out-patients clinic: is the contribution of the hard-to-culture microbiota overlooked in gynaecological disorders? Aust NZ J Obstet Gynaecol 2005;45:450-2.

21. Swidsinski A, Mendling W, Loening-Baucke V, et al. Adherent biofilms in bacterial vaginosis. Obstet Gynecol 2005;106:1013-23.

22. Kiviat NB, Wolner-Hanssen P, Eschenbach DA, et al. Endometrial histopathology in patients with culture-proven upper genital tract infection and laparoscopically diagnosed acute salpingitis. Am J Surg Pathol 1990;14:167-75.

23. Geissdorfer W, Bohmer C, Pelz K, et al. Tuboovarian abscess caused by Atopobium vaginae following transvaginal oocyte recovery. J Clin Microbiol 2003;41:2788-90.

24. Hanff PA, Rosol-Donoghue JA, Spiegel CA, et al. Leptotrichia sanguinegens sp. nov., a new agent of postpartum and neonatal bacteremia. Clin Infect Dis 1995;20(Suppl 2):S237-9.

25. Gundi VA, Desbriere R, La Scola B. Leptotrichia amnionii and the female reproductive tract. Emerg Infect Dis 2004;10:2056-7.

26. Shukla SK, Meier PR, Mitchell PD, et al. Leptotrichia amnionii sp. nov., a novel bacterium isolated from the amniotic fluid of a woman after intrauterine fetal demise. J Clin Microbiol 2002;40:3346-9.

27. Hebb JK, Cohen CR, Astete SG, et al. Detection of novel organisms associated with salpingitis, by use of $16 \mathrm{~S}$ rDNA polymerase chain reaction. J Infect Dis 2004; 190:2109-20.

28. Fredricks DN, Fiedler TL, Thomas KK, et al. Targeted PCR for detection of vaginal bacteria associated with bacterial vaginosis. J Clin Microbiol 2007;45:3270-6. 